\title{
Utilization of Agrowaste Polymers in PVC/NBR Alloys: Tensile, Thermal, and Morphological Properties
}

\author{
Ahmad Mousa, ${ }^{1}$ Gert Heinrich, ${ }^{2}$ Bernd Kretzschmar, ${ }^{2}$ Udo Wagenknecht, ${ }^{2}$ and Amit Das ${ }^{2}$ \\ ${ }^{1}$ Department of Materials Engineering, Faculty of Engineering, Al Balqa Applied University, Salt 19117, Jordan \\ ${ }^{2}$ Leibniz-Institut für Polymerforschung Dresden e.V., Hohe Straße 6, 01069 Dresden, Germany \\ Correspondence should be addressed to Ahmad Mousa, mousa@rocketmail.com
}

Received 11 October 2011; Revised 25 January 2012; Accepted 2 February 2012

Academic Editor: Licínio M. Gando-Ferreira

Copyright (C 2012 Ahmad Mousa et al. This is an open access article distributed under the Creative Commons Attribution License, which permits unrestricted use, distribution, and reproduction in any medium, provided the original work is properly cited.

\begin{abstract}
Poly(vinyl chloride)/nitrile butadiene rubber (PVC/NBR) alloys were melt-mixed using a Brabender Plasticorder at $180^{\circ} \mathrm{C}$ and $50 \mathrm{rpm}$ rotor speed. Alloys obtained by melt mixing from PVC and NBR were formulated with wood-flour- (WF-) based olive residue, a natural byproduct from olive oil extraction industry. WF was progressively increased from 0 to 30 phr. The effects of WF loadings on the tensile properties of the fabricated samples were inspected. The torque rheometry, which is an indirect indication of the melt strength, is reported. The pattern of water uptake for the composites was checked as a function WF loading. The fracture mode and the quality of bonding of the alloy with and without filler are studied using electron scanning microscope (SEM).
\end{abstract}

\section{Introduction}

Polymer alloys continue to represent a field of intensive research. One of the most common blends in the modern sense is PVC with NBR $[1,2]$. Due to the miscible nature of PVC/NBR blend as evidenced from single glass transition $\left(T_{g}\right)$ the soft blend of PVC/NBR can be categorized as a thermoplastic elastomer (TPE) and more specifically as a melt processable rubber (MPR) [3-5]. Fillers are incorporated mainly to improve service properties or to reduce material cost depending on the source of filler, type of filler, method of preparation, and treatment. Very large quantities of the natural lignocelluloses polymers are produced annually as agrowastes. A very small amount is used as antioxidants or fillers in polymers. The rest is used almost as fuel to generate energy. The field of wood-based agrowastes polymer composites is extensively reviewed in the open literature [5-8]. Recently, we report the effect of virgin olive pomace on the flexural and thermal performance of toughened PVC composites [9]. We found that the virgin olive pomace enhanced the flexural properties to a certain extent, which was due to the hydrogen bond formation, while the thermal stability was improved due to the phenolic hydroxyl group within the lignocellulosic powder. In this work, the effect of wood-flour-based olive residue on the tensile properties, water absorption and morphology of PVC/NBR alloys are reported in the current investigation.

\section{Experimental}

2.1. Materials and Formulation. Acrylonitrile nitrile rubber with 34\% acrylo content was supplied by Bayer AG, Germany. Suspension PVC grade in powder form with a $k$-value of 67 was supplied by SABIC of Saudi Arabia and stabilized with lead salt. Wood-flour-based agrowastes with particle size equal or less than $45 \mu \mathrm{m}$ were used as received. The WF-based olive mill residue has been fully characterized and reported earlier; the major reactive functional group with its structure was the hydroxyl group from the cellulose and hemicellulose $[10,11]$. The samples were formulated according to the following recipe: NBR: 20\% PVC: $80 \%$, WF: various in part per hundred-part polymer (php), that is, the filler loading was based on the total amount of resin (PVC) and elastomer (NBR), which is 100 parts.

2.2. Sample Preparation. Mixing was carried out at $180^{\circ} \mathrm{C}$ and $50 \mathrm{rev} \cdot \mathrm{min}^{-1}$ rotor speed using a computerized 
brabender plasticorder Model PLE 331 for 8 minutes. The NBR was initially loaded into the mixing chamber of Brabender for one minute, followed by PVC and the wood flour.

2.3. Torque Rheometry. Melt rheological properties of the prepared blends were evaluated using a Brabender Plasticorder at the predetermined mixing variables. Mixing was continued until torque and temperature were stabilized to constant values of $8-10 \mathrm{~min}$ at $50 \mathrm{rev} / \mathrm{min}$ as the optimum mixing shear. The effect of WF loading on the shear heating $(\Delta T)$ in a Brabender Plasticorder results in temperature rise given as: $\Delta T=$ melt temperature - set temperature. Mixing was performed until constant stabilization torque and temperatures values were recorded.

2.4. Tensile Properties. Tensile properties were carried out according to ASTM D638. The dumbbells specimens were cut from $2 \mathrm{~mm}$ thick molded sheets of wood-flour-filled PVC/NBR alloys. Five specimens were tested, and the median value was taken for each formulation.

2.5. Water Absorption. $2 \mathrm{~mm}$ thick rectangular samples were weighed in air. The samples were immersed in distilled water for seven days at room temperature. The samples were removed from water, wiped with tissue paper, and reweighed. The \% water uptake was calculated according to the following equation:

$$
\% \text { Water uptake }=\frac{W_{2}-W_{1}}{W_{1}} \times 100,
$$

where $W_{1}$ is the sample weight in air and $W_{2}$ is the weight after immersion. The average of three samples was calculated.

2.6. Thermal Analysis. The composites were scanned by a Perkin-Elmer DSC-6 differential scanning calorimeter (DSC) in the range of -40 to $100^{\circ} \mathrm{C}$ at heating rate of $5^{\circ} \mathrm{C} / \mathrm{min}$.

2.7. Failure Mode. To check the failure mode and the quality of bonding the surfaces of the tensile fractured samples were viewed under scanning electron microscope (SEM) model (geol Tokyo, Japan). The specimens were sputtered with AuPd alloy prior to scanning to avoid electrostatic charges.

\section{Results and Discussions}

Figure 1 shows the effect of WF loading on tensile modulus of PVC/NBR alloy. It can be seen that tensile modulus increased steadily with filler loading. This trend is in line with earlier work on rigid and toughened PVC $[9,10]$. The observed trend recorded in Figure 1 could be attributed to the reduction in free volume between the chains of the PVC/NBR alloy. Reduction in the free volume with filler loading leads to the observed trend shown in Figure 1. Figure 2 shows the influence of WF on the yield tensile strength of the PVC/NBR alloy as a function of filler loading. It is clear that the yield tensile strength decreased with WF loading.

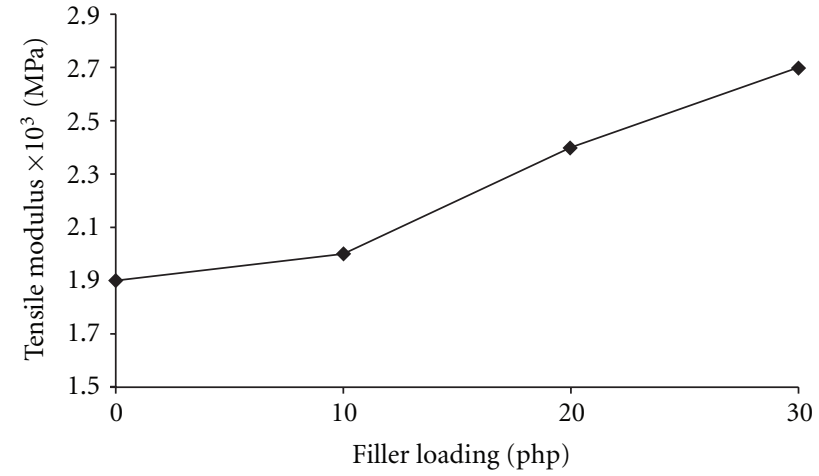

Figure 1: The influence of filler loading on tensile modulus of PVC/NBR alloy.

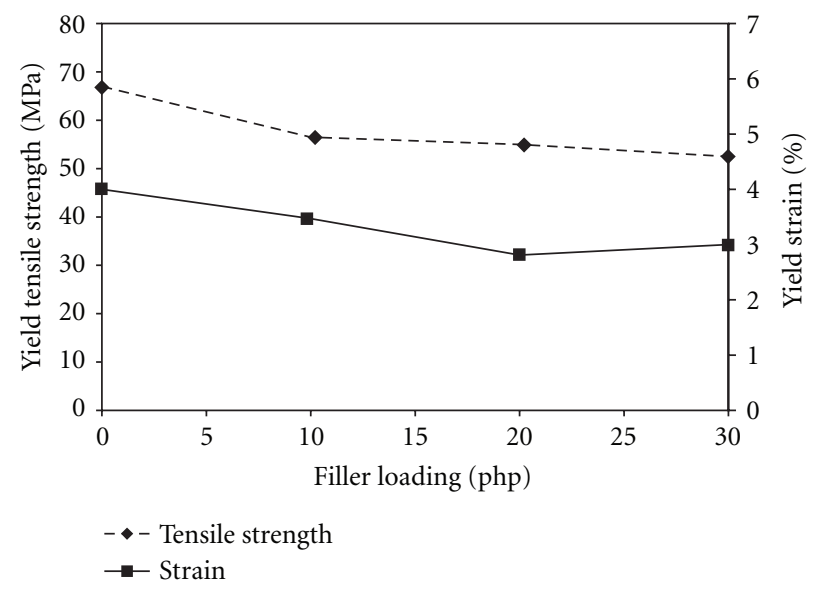

FIGURE 2: The influence of filler loading on the yield tensile strength of PV/NBR alloy.

Such observation might be due to the inability of WF to transfer the stress, possibly due to improper filler dispersion in the matrix and moisture pick-up which lead to insufficient interfacial bonding between the alloy and the filler.

Similar trends were recorded in the case of percentage strain at yield shown in Figure 2. Again this might be due to the rigidity of the PVC/NBR filled with WF due to the rigidity of the filler itself. The progress of the stock temperature as a function of WF loading is represented in Figure 3 for the PVC/NBR alloy. One can see that the stock temperature increased with WF loading over the set processing conditions. However, the extensive shearing causes the stock temperature to rise steeply above the mixing temperature even at the end of the 8th min of the mixing time, until the stock temperature undergoes a steady value. Interestingly, the equilibrium torque displayed in Figure 3, which is an indirect indication of the melt strength, showed a higher value with addition of WF as compared to the control sample. This suggested that the addition of WF has slightly restricted the mobility of the alloy due to the interaction between the matrix and the filler and hence increased the 


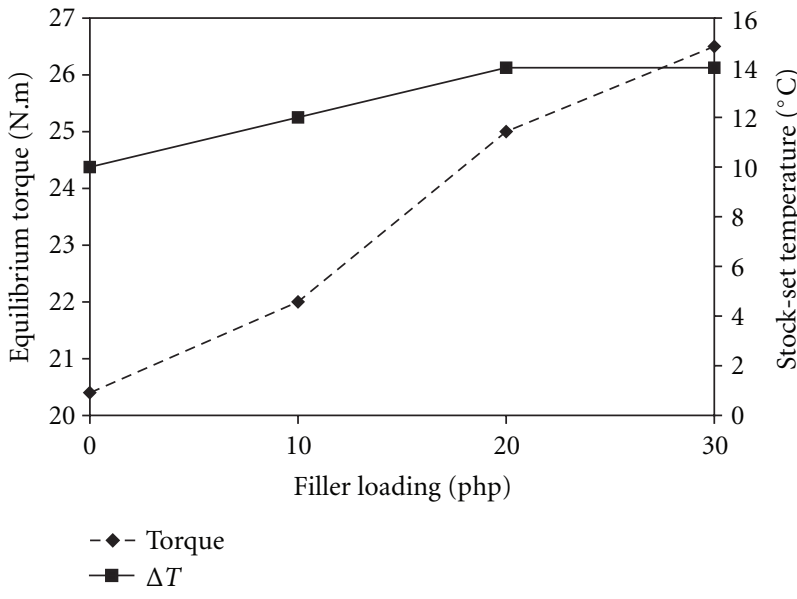

FIGURE 3: The influence of WF loading on the equilibrium torque and stock temperature of PV/NBR alloy.

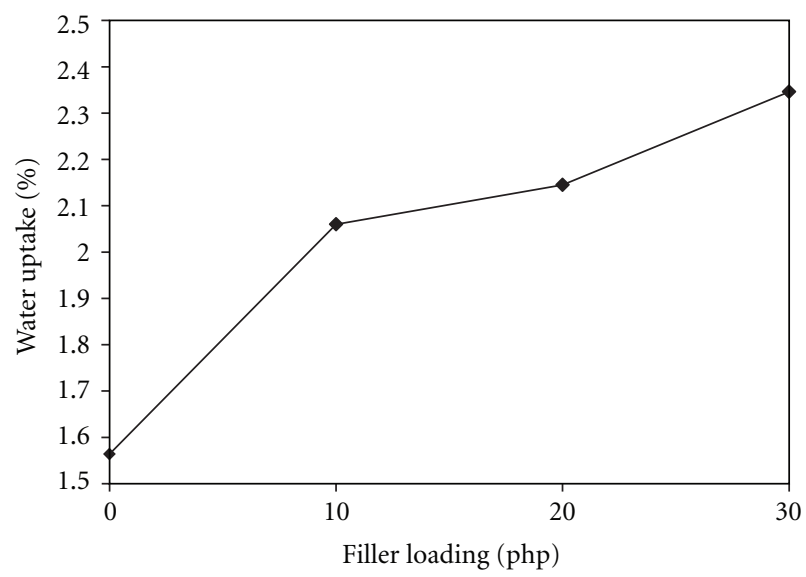

FIgURE 4: The influence of WF loading on \% water uptake of PV/NBR alloy.

melt strength. Such finding suggests that certain types of interactions between the filler and the matrix have occurred, such interactions are expected to slightly restrict the mobility of the alloy chains and increased the torque. Figure 4 shows the water absorption behavior of the PVC/NBR alloy as a function of filler loading. It can be seen that water absorption has increased with WF content. This is mainly due to hydroxyl content of the WF. The low uptake in case of the unfilled composite could be due to the hydrophobic nature of the polymer.

3.1. Thermal Analysis. Figure 5 illustrates DSC curves (first run) for PVC/NBR control and for the composite with WF at 20 php loading of filler loading. Looking at the DSC curves presented in Figure 5 at the $-40-90^{\circ} \mathrm{C}$ temperature interval, one can see that the endotherm peak was detected. Such peak was shifted to the right by the incorporation of the WF loading. One may conclude that this peak is caused by

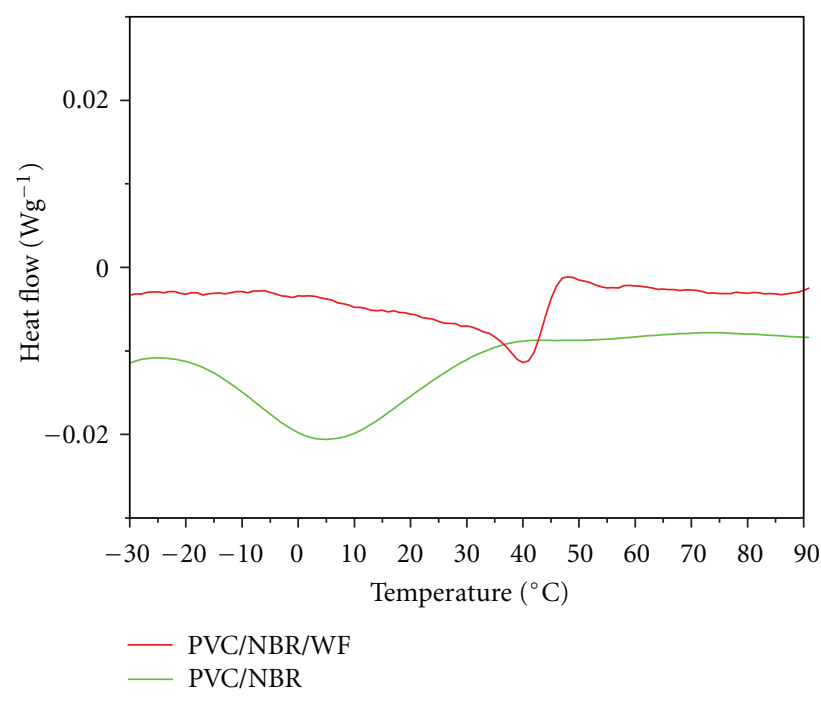

FIGURE 5: DSC traces of PVC/NBR alloy with and without WF.

molecular relaxation of the PVC/NBR alloy. Note that the addition of WF has delayed the molecular relaxation of the alloy. This should be related to the interaction between the WF and the PVC/NBR alloy via polar-polar interaction as reported earlier $[9,10]$.

3.2. SEM. Interfacial interactions and the strength of adhesion determine micromechanical deformation processes and the failure mode of the composites [11, 12]. The SEM micrographs that were taken from the surfaces of broken specimens offer indirect information about the failure mode and bonding quality. Figure 6(a) presents the fracture surface of the plain blend. It can bee seen that the system is one phase with some particles that come from ingredients added to the PVC compound such as stabilizers and so forth. Figure 6(b) shows the fracture surface of sample with $10 \mathrm{php}$ filler. It can be seen that the wood is covered with the polymer and the relatively small number of holes related to debonding or fiber pull-out indicates good adhesion. On the other hand, the opposite is observed in composites prepared with the higher amounts of filler doses, namely, 20 and $30 \mathrm{php}$ loading, respectively, as shown in Figures 6(c) and 6(d). The number of debonded particles is quite large, the contours of particles remaining on the surface of the matrix are sharp, and adhesion seems to be poor, at least compared to Figure 6(b).

\section{Conclusions}

Based on this paper it can be concluded that pristine WF has improved the tensile modulus of the blend whereas the tensile strength remained more or less the same. It also can be concluded that the filler has good degree of interactions as indicated by the torque data obtained from the Brabender plasticorder. The DSC traces showed that the molecular relaxation of the blend was hindered with the presence of the WF. SEM micrographs showed that the failure mode was due 


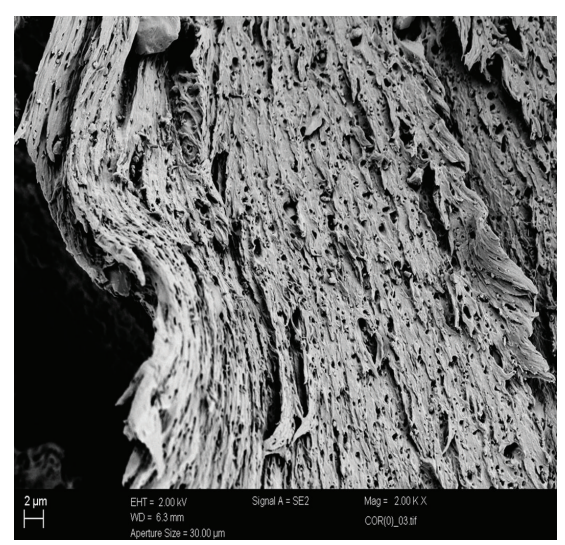

(a)

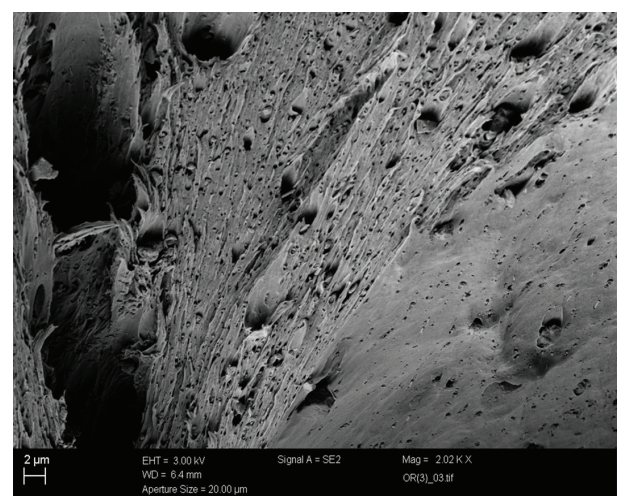

(c)

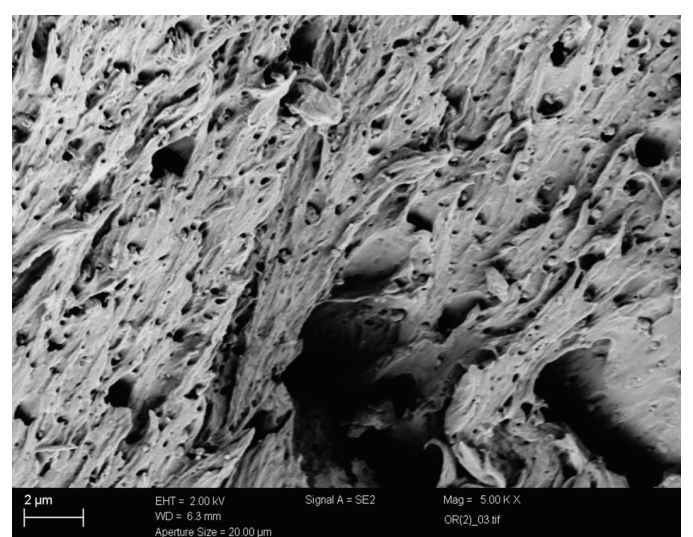

(b)

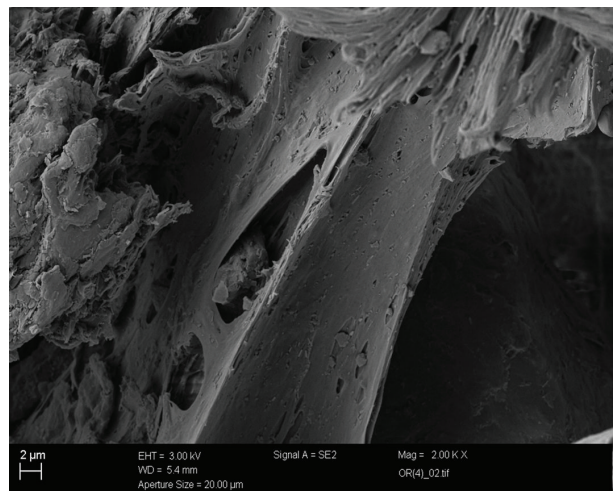

(d)

FIgURE 6: Scanning electron microscope images of (a) plain PVC/NBR alloy (b) PVC/NBR at 10 php filler loading, (c) 20 php filler, and (d) 30 php filler.

to the pull-out of the filler; furthermore, higher loading of the WF has led to agglomeration.

\section{References}

[1] L. A. Utracki, D. J. Walsh, and R. A. Weiss, "Polymer alloys, blends, and Ionomers: an overview," in Multiphase Polymers: Blends and Ionomers, L. A. Utracki and R. A. Weiss, Eds., vol. 395 of ACS symposium Series, pp. 1-35, American Chemical Society, Washington, DC, USA, 1989.

[2] K. T. Varughese, P. P. De, S. K. Sanyal, and S. K. De, "Miscible blends from plasticized poly(vinyl chloride) and epoxidized natural rubber," Journal of Applied Polymer Science, vol. 37, no. 9, pp. 2537-2548, 1989.

[3] Y. Song, Q. Zheng, and C. Liu, "Green biocomposites from wheat gluten and hydroxyethyl cellulose: processing and properties," Industrial Crops and Products, vol. 28, no. 1, pp. 56-62, 2008.

[4] G. Siracusa, A. D. la Rosa, V. Siracusa, and M. Trovato, "Eco-compatible use of olive husk as filler in thermoplastic composites," Journal of Polymers and the Environment, vol. 9, no. 4, pp. 157-161, 2001.

[5] A. Abu Bakar, A. Hassan, and A. F. M. Yusof, "Effect of oil palm empty fruit bunch and acrylic impact modifier on mechanical properties and prcessability of unplasticized poly (vinyl chloride) composites," Polymer-Plastics Technology and Engineering, vol. 44, pp. 1125-1137, 2005.

[6] H. D. Rozman, G. S. Tay, R. N. Kumar, A. Abusamah, H. Ismail, and Z. A. Mohd, "The effect of oil extraction of the oil palm empty fruit bunch on the mechanical properties of polypropylene-oil palm empty fruit bunch-glass fibre hybrid composites," Polymer-Plastics Technology and Engineering, vol. 40, no. 2, pp. 103-115, 2001.

[7] Z. A. M. Ishak, A. Aminullah, H. Ismail, and H. D. Rozman, "Effect of silane-based coupling agents and acrylic acid based compatibilizers on mechanical properties of oil palm empty fruit bunch filled high-density polyethylene composites," Journal of Applied Polymer Science, vol. 68, no. 13, pp. 21892203, 1998.

[8] L. Avérous and F. le Digabel, "Properties of biocomposites based on lignocellulosic fillers," Carbohydrate Polymers, vol. 66, no. 4, pp. 480-493, 2006.

[9] A. Mousa, G. Heinrich, U. Gohs, R. Hässler, and U. Wagenknecht, "Application of renewable agro-waste-based olive pomace on the mechanical and thermal performance of toughened PVC," Polymer-Plastics Technology and Engineering, vol. 48, no. 10, pp. 1030-1040, 2009.

[10] A. Mousa, G. Heinrich, and U. Wagenknecht, "Thermoplastic composites based on renewable natural resources: unplasticized PVC/olive husk," International Journal of Polymeric Materials, vol. 59, no. 11, pp. 843-853, 2010. 
[11] T. G. Vladkova, P. D. Dineff, and D. N. Gospodinova, "Wood flour: a new filler for the rubber processing industry. II. Cure characteristics and mechanical properties of NBR compounds filled with corona-treated wood flour," Journal of Applied Polymer Science, vol. 91, no. 2, pp. 883-889, 2004.

[12] L. Fama, A. Mônica, B. Q. Bittante, P. J. A. Sobral, S. Goyanes, and L. N. Gerschenson, "Garlic powder and wheat bran as fillers: their effect on the physicochemical properties of edible biocomposites," Materials Science and Engineering C, vol. 30, no. 6, pp. 853-859, 2010. 

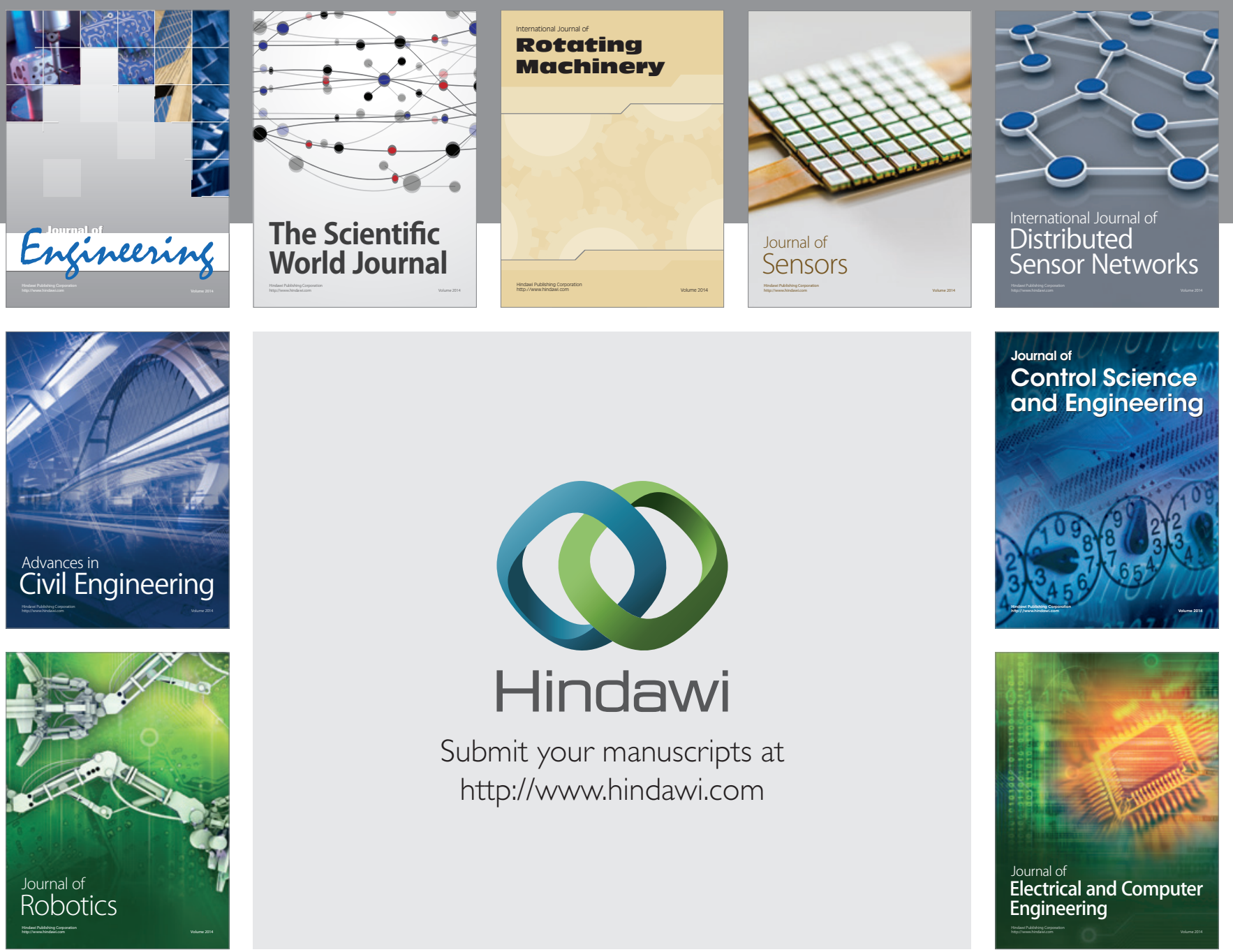

Submit your manuscripts at

http://www.hindawi.com
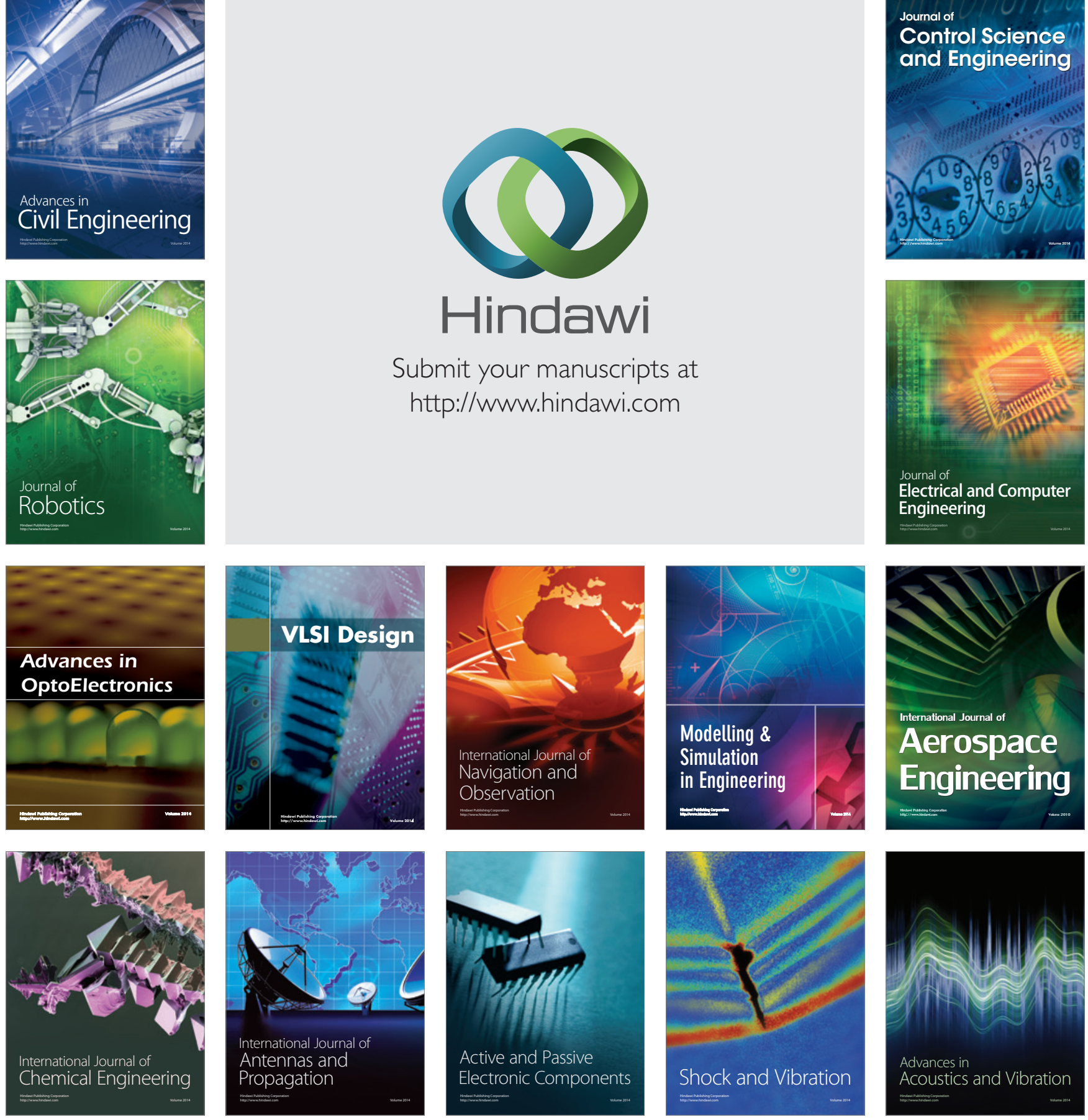